\title{
EDITORIAL
}

\section{Transformations of identity and space in the Middle East and North Africa}

$\mathrm{T}$ he current issue of Approaching Religion includes articles based on conference papers presented at the Fifth Finnish Colloquium on the Middle East and North Africa Studies, which was organised by the Finnish Institute in the Middle East (FIME), the University of Eastern Finland, Faculty of Theology, and the University of Helsinki, including the Academy of Finland Centre of Excellence Changes in Sacred Texts and Traditions, in Joensuu, 29-31 May 2017. The theme of the conference was 'Transformations of Identity and Space in the Middle East and North Africa', and it explored the construction and transformation of identity in space, whether geographical, mental or virtual.

The Finnish Institute in the Middle East initiated the Finnish Colloquiums as one of its primary activities in Finland, with a specific objective of strengthening its partnerships and enhancing Middle Eastern and North African studies in Finland. FIME is an academic institute that focuses on the study of Middle Eastern cultures, religions, societies and classic and modern languages. The Institute supports Finnish research on the Middle East and co-operates with universities and research institutions in related fields of research and study. In the Middle East, the Institute is based in Beirut, Lebanon.

The issue opens with Mikko Pisiläs article 'Vicarious dissonance and the narrative of the Gospel of Matthew. By applying approaches from social psychological and narrative-critical research, the article seeks to demonstrate the ability of the gospel narrative to transform the social identity of the audience and stimulate group commitment by way of vicarious cognitive dissonance.

The following two articles deal with early Eastern Christianity and its polemic relationship to its 'others'. In his article, Fr Damaskinos (Olkinuora) of Xenophontos analyses the writings of the eighthcentury theologian and writer John Damascene, who lived and worked as a civil servant of the Umayyad Caliphate. The article analyses his treatise on the socalled Trisagion, a hymn, which became a symbol for the controversy between rivalling interpretations of the Christian creed of the trinity at the time. Thereafter, Serafim Seppälä analyses early Christian polemics against Islam. Focusing on two authors, Theodore Abū Qurrah (9th century) and 'Abd al-Jabbār (1 oth century) he analyses how historical arguments are used to prove or disprove the truthful and divine character of Christianity.

The following two articles deal with ethnographic perspectives on contemporary religiosity in the Middle East. Based on her anthropological field research, Päivi Miettunen describes and analyses the role and agency of local Bedouin women in the traditions connected to holy pilgrimage sites in South Jordan. Mari Johanna Parkkinen, on her part, describes and analyses prayer practices among Palestinian Christians in the Occupied Palestinian Territory. Based on interviews conducted in the field, Parkkinen demonstrates how prayer enables people to cope in stressful life situations and how prayer types are utilised across generations in the current context.

Taken together, the papers demonstrate the interdisciplinary breadth, theoretical variety and 
methodological multitude of the research on themes relating to the Middle East currently being conducted in Finland. We hope that you will find the issue to be an elucidating as well as enjoyable read.

RAIJA MATTILA and RUTH ILLMAN Guest Editor and Editor-in-Chief

Raija Mattila is Docent of Assyriology at the University of Helsinki. She is the director of the Finnish Institute in the Middle East based in Beirut, Lebanon.
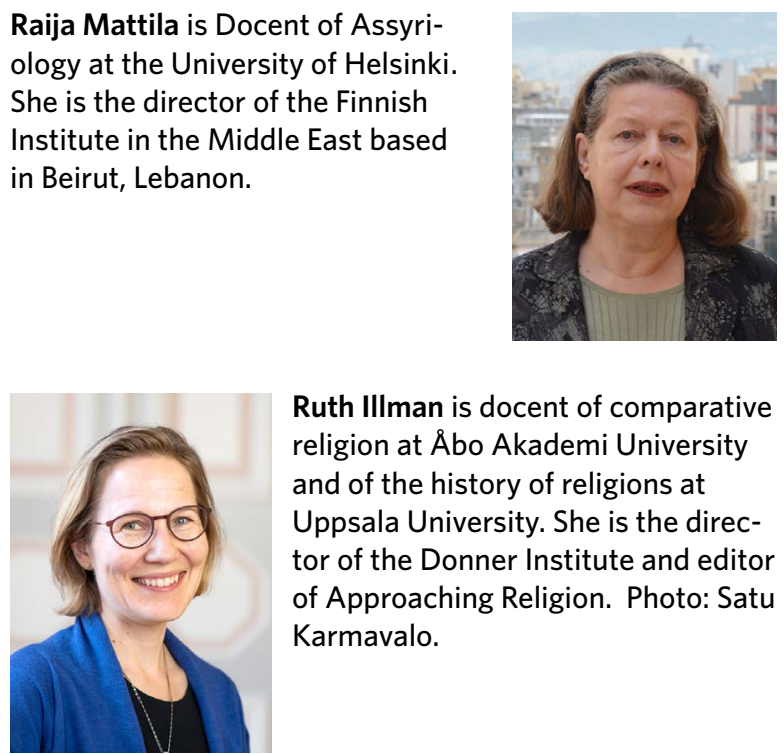

Ruth Illman is docent of comparative religion at Åbo Akademi University and of the history of religions at Uppsala University. She is the director of the Donner Institute and editor of Approaching Religion. Photo: Satu Karmavalo. 